\title{
SENSIBILIDADE ANTIMICROBIANA DE Staphylococcus aureus ISOLADOS DE AMOSTRAS DE LEITE DE VACAS COM MASTITE SUBCLÍNICA
}

\author{
ANTIMICROBIAL SENSITIVITY OF Staphylococci aureus ISOLATED OF MASTITIS \\ SUBCLINICAL IN COWS MILK SAMPLES
}

\author{
G. A. FIM JÚNIOR ${ }^{1 *}$, C. O. VASO ${ }^{2}$, A. B. SEIXAS ${ }^{2}$, N. S. S. LOPES ${ }^{2}$, L. E. PILON ${ }^{1}$,
} R. C. M. SANTANA ${ }^{3}$, C. C. LANGE ${ }^{4}$, L. F. ZAFALON ${ }^{3}$

\section{RESUMO}

O objetivo do estudo foi investigar a sensibilidade antimicrobiana de Staphylococcus aureus isolados de quartos mamárias de vacas com mastite subclínica. As amostras de leite foram colhidas de vacas oriundas de rebanhos localizados nas regiões norte, noroeste e central do estado de São Paulo, que apresentavam diferentes estágios de lactação. A identificação prévia da mastite subclínica foi feita por meio do California Mastitis Test (CMT), realizado após o teste da caneca de fundo escuro. Os tetos foram higienizados (prédipping) e secos com papel toalha. Após a desinfecção do óstio papilar com álcool 70\%, amostras de $5 \mathrm{~mL}$ de leite de cada quarto mamário foram colhidas em tubos esterilizados e encaminhadas aos laboratórios da Embrapa Pecuária Sudeste, em São Carlos. A identificação microbiológica foi feita de acordo com as características morfotintoriais e bioquímicas dos micro-organismos, que foram posteriormente submetidos aos testes de sensibilidade in vitro a partir da técnica de difusão de disco. Utilizou-se 17 princípios ativos antimicrobianos: amicacina (30ug), ampicilina (10ug), cefalotina (30ug), cefepima $(30 \mu \mathrm{g})$ ceftazidima (30ug), ciprofloxacina $(5 \mu \mathrm{g})$, clindamicina $(2 \mu \mathrm{g})$, cloranfenicol $(30 \mu \mathrm{g})$, cotrimoxazol $(25 \mu \mathrm{g})$, eritromicina $(15 \mu \mathrm{g})$, gentamicina $(10 \mu \mathrm{g})$, oxacilina $(1 \mu \mathrm{g})$, penicilina $(10 \mathrm{Ul})$, rifampicina $(5 \mu \mathrm{g})$, tetraciclina $(30 \mu \mathrm{g})$, tobramicina (10ug) e vancomicina $(30 \mu \mathrm{g})$.Sessenta e nove amostras de Staphylococcus aureus originados de 127 vacas foram investigados. Os maiores percentuais de sensibilidade apresentados foram à gentamicina, cefepima, cotrimoxazol, tetraciclina, tobramicina, cloranfenicol, rifampicina, cefalotina, oxacilina, amicacina, vancomicina e clindamicina $(100,0 \%, 100,0 \%, 100,0 \%, 100,0 \%, 100,0 \%, 100,0 \%, 100,0 \%, 100,0 \%, 98,2 \%$, $96 \%, 95,7 \%$ e $95,7 \%$ respectivamente), enquanto os maiores percentuais de resistência foram à penicilina, ampicilina e ceftazidima $(89,2 \%, 56,0 \%, 28,0 \%$, respectivamente).A realização de testes de sensibilidade in vitro em micro-organismos envolvidos na etiologia infecciosa da mastite é relevante para o tratamento dos animais e acompanhamento da epidemiologia da doença.

PALAVRAS-CHAVE: MASTITE BOVINA. MICRO-ORGANISMOS. REBANHOS. RESISTÊNCIA

ÁREA TEMÁTICA: Doenças Infecciosas

\footnotetext{
${ }^{1}$ Faculdade de Ciências Agrárias e Veterinárias da Universidade Estadual Paulista (UNESP) - Campus de Jaboticabal, Jaboticabal, SP * guilhermejunior10@ hotmail.com

${ }^{2}$ Centro Universitário Central Paulista (UNICEP), São Carlos, SP

${ }^{3}$ Embrapa Pecuária Sudeste, São Carlos, SP

${ }^{4}$ Embrapa Gado de Leite, Juiz de Fora, MG
} 